\title{
Valorization on the energy potential of Pistia stratiotes in sustainable agriculture-review
}

\author{
Andreea Matache ${ }^{1 *}$, Nicoleta Alexandra Vanghele $^{1}$, Mihai Gabriel Matache ${ }^{1}$ and Ancuța \\ Alexandra Petre $^{1}$ \\ ${ }^{1}$ The National Institute of Research - Development for Machines and Installations designed to \\ Agriculture and Food Industry - INMA Bucharest
}

\begin{abstract}
Of late years, aquatic plants have received increased attention due to their energy potential in sustainable agriculture. Pistia stratiotes also belongs to this category. A vital aspect in sustainable agriculture, to which there is a growing tendency, is the use of environmentally friendly methods. Aquatic plants are used as raw materials for various applications, such as food industry, health, agriculture and aquaculture, ecosystem management, being an essential renewable resource. Due to population growth, both developed and developing countries are mainly facing problems related to future energy security and the proper use of natural resources. As the search for renewable energy resource intensifies, there is a growing drive to identify and develop promising, environmentally friendly, low-carbon and low-carbon bioenergy raw materials. Fuel demand is rising, while food costs and waste are gradually rising. It is therefore necessary to address waste management and reduce pollution caused by excessive energy use and industrialization. The current study focuses on the potential for harnessing renewable energy in the Nile lettuce (Pistia stratiotes), namely, highlighting the process of residual biomass, biofuel and compost.
\end{abstract}

Keywords: aquatic plants, sustainable agriculture, energy potential, Pistia stratiotes

\section{Introduction}

With the demographic development and increasing consumption, agricultural production is also constantly evolving. Classical agriculture uses numerous resources and various tillage operations that involve the use of significant amounts of water, fertilizers, pesticides [1]. As a major consumer of biodiversity, agriculture must constantly turn to new renewable resources. Special efforts are being made to implement efficient technologies, meant to support the evolution of classical agriculture toward a sustainable one $[2,3]$.

Sustainable agriculture offers the opportunity to exploit natural resources ecologically and analyze the principles of nature to develop their own systems of breeding crops and animals $[4,5]$. The exploitation of renewable resources becomes essential in the context of the permanent decline of nonrenewable resources [6].

\footnotetext{
* Corresponding author: andmatache@yahoo.com
} 
An important renewable resource is biomass, which includes residues from various activities: agriculture, forestry, animal husbandry, food and industrial waste. The energy potential of biomass is known, but being an intensively exploited resource, attention should be paid to the use of residual biomass available as an alternative energy source $[7,8]$. fuels [9].

Biomass is also a renewable source in the context of long-term exploitation of fossil

Fuels obtained using organic practices, such as agriculture and anaerobic digestion, are considered biofuels. The biofuel is formed by the biological fixation of carbon. While fossil fuels are considered nonrenewable, biofuels are a renewable source [10]. The category of biofuels includes ethanol, biodiesel, methanol, biobutanol [11]. Due to environmental requirements, there is a growing interest in the use of biofuels. Using them can also bring benefits by extending the life of engines, especially diesel [12].

Another way to use biomass is to use it to enrich the compost with nutrients, thus becoming biocompost. Composting is often presented as a form of recycling nature. Composting differs from natural decomposition by human control over the process of biological decomposition of organic matter. This results in a quality compost in a shorter time $[13,14]$.

Composting has become an alternative for treating organic waste to obtain a sanitized final material that can be used on any scale [15].

Knowing their energy potential in sustainable agriculture, aquatic plants have come to the attention of scientists interested in developing efficient and environmentally friendly techniques.

Although the Pistia stratiotes is known as an invasive aquatic plant, it also has multiple favorable uses. It is used as an ornamental species for aquariums, in phytoremediation of chemicals and metals and for wastewater treatment. Biomass from Pistia stratiotes can be exploited for feed production, compost, biogas [16].

By raising awareness of renewable energy resources, markets and scientific studies, the economy can become cleaner and more sustainable [17].

In this paper it is presented the energetic potential of the aquatic plant Pistia stratiotes.

\section{Materials and methods - means of valorization}

Nile lettuce (Pistia stratiotes) is considered an invasive floating macrophyte and therefore its control methods are sought. Despite all these negative aspects, several researchers demonstrate that $\mathrm{P}$. stratiotes is an energy source.

\section{Biomass}

In Slovenia (Lake Sava), Pistia stratiotes biomass with chemical and physical parameters and seed resistance were analyzed to study the sustainability and spread of the species. Lake Sava has a special water temperature regime due to the underground thermal springs and the flow of hot water from the basins of a neighboring resort. The study area was divided into five sections (A, B, C, D, E) according to temperature differences. with application in the production of biofuel, bioenergy, fertilizer and compost [18].

\section{Biofuels}

In study [19], is presented the potential, by photofermentation, of the residual biomass of Pistia stratiotes to produce biofuel from hydrogen. This analysis was performed following the nitrogen removal treatment. A natural strain and a processed strain of Rhodopseudomonas palustris were used to determine the hydrogen. The use of Pistia 
stratiotes in the bioenergetic branch is largely based on its high productivity. The resulting composition was used for cultivating R. palustris. The natural strain adapted more easily, having a higher biochemical hydrogen yield than the processed strain.

The results obtained show that after the elimination of ammonium, fermentation and hydrolysis, the residual biomass of Nile lettuce (Pistia stratiotes) has considerable potential for the production of biofuels [19].

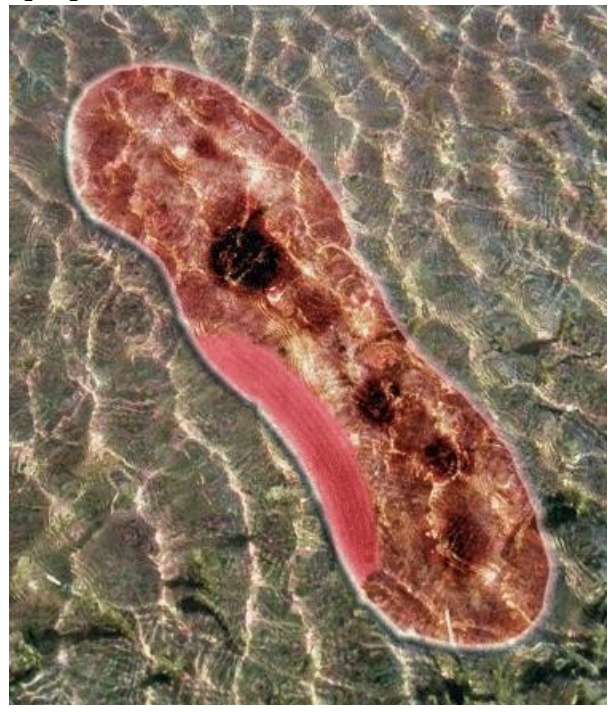

Fig. 1. Metabolic processes in Rhodopseudomonas palustris [27].

Biomass of Pistia stratiotes can be introduced as a substrate for bioethanol production due to the growth rate. Another advantage is the soft consistency of the plant, which facilitates its grinding process, to increase its biochemical reaction capacity. For enzymatic hydrolysis and fermentation of pretreated biomass of Pistia stratiotes to obtain ethanol, the researchers applied two fermentation methods, concomitant saccharification and fermentation (SSF) and separate hydrolysis and fermentation (SHF).

The fermentation microorganisms were Escherichia coli recombinant and Saccharomyces cerevisiae. Research results show that Pistia stratotes biomass has an increased yield in ethanol production when the fermentation process is improved [20].

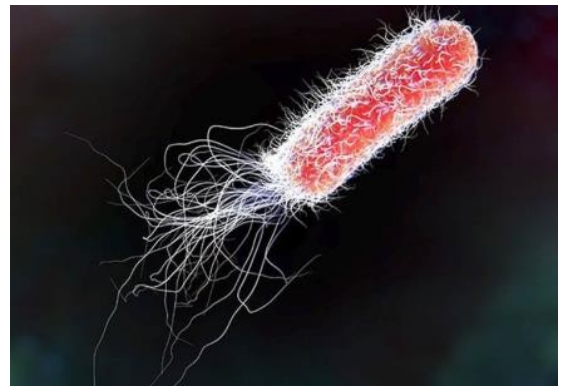

Fig. 2. Escherichia coli [28].

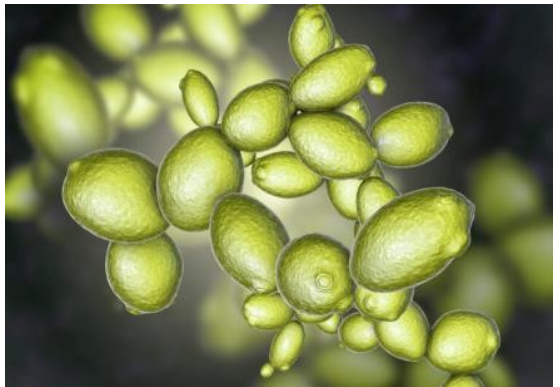

Fig. 3. Saccharomyces cerevisiae [29]. 
For the best possible management of fossil carbon emissions the focus is on new renewable sources. Therefore, in study [21] the biomass of Nile lettuce is analyzed, to produce bioethanol. Fresh and dried Pistia stratiotes biomass was administered with acid $\left(\mathrm{H}_{2} \mathrm{SO}_{4}\right)$ and alkali $(\mathrm{NaOH})$. These were mixed to pre-treat the free floating macrophyte biomass.

In the wild, Pistia stratiotes gathers starch-shaped food. After pre-treating the Nile salad with cellulose, ethanol (15.385 g / L), reducing sugar $(4.773 \pm 0.15 \%)$ and total sugar $(11.350 \pm 0.09 \%)$ were obtained. As a result, P. stratiotes has considerable potential in bioethanol production. In fig. 4 is presented graphically, the process of producing bioethanol from Pistia stratiotes biomass.

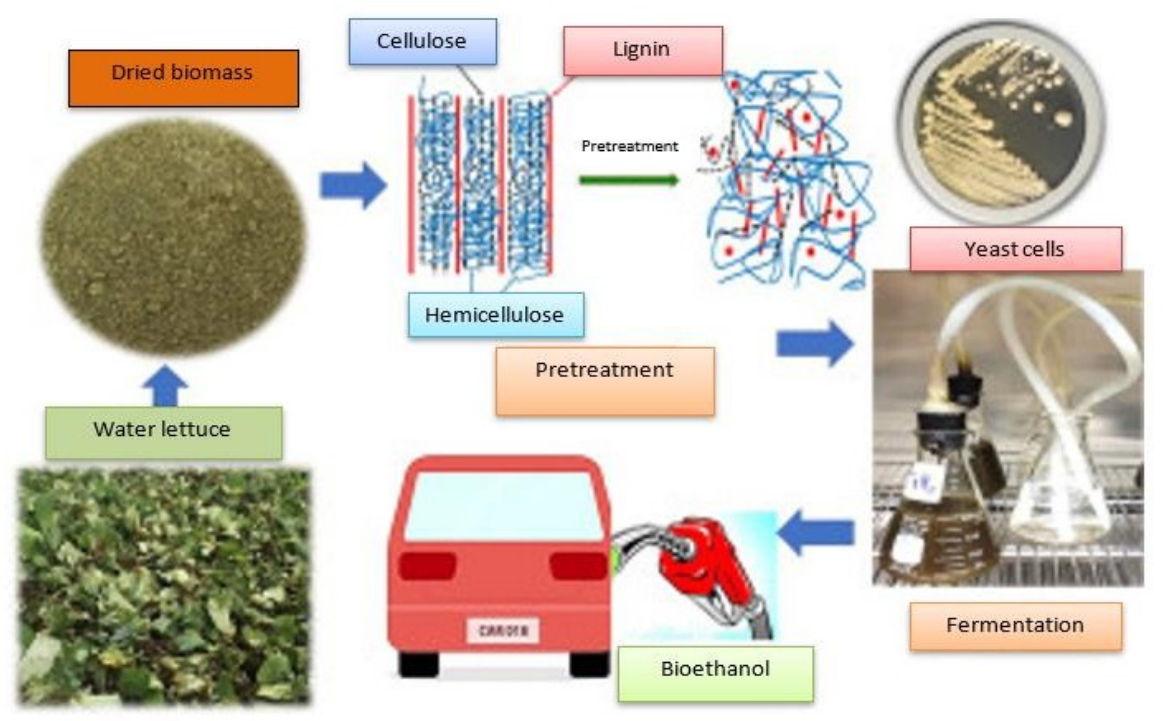

Fig. 4. Graphic presentation of bioethanol production from Pistia stratiotes biomass [21].

The following reserch paper analyzes Pistia stratiotes biomass to obtain biofuel [22]. The procedure was structured in 4 steps: 1 . From the separated, washed and chopped leaves and roots resulted the juice; 2. The juice, then mixed with various concentrations of hydrochloric acid (HCL), was heated to $120^{\circ} \mathrm{C}$ for an average of $10 \mathrm{~min}$. After cooling, the sample was filtered and collected; 3 . At an average temperature of $35^{\circ} \mathrm{C}$, fermentation began by adding dry yeast. 4 . At the end of the fermentation process, distillation was conducted using steam and liquefaction. After that, the alcohol esterification process began with the use of a biodiesel separation impulse.

\section{Energy (bioelectricity in hybrid system)}

Increasing energy consumption from nonrenewable sources has led to the focus on new renewable energy sources. Paper [23], presents the ability of aquatic and terrestrial plants (Ipomoea aquatica and Pistia stratiotes) to simultaneously produce biomass and bioelectricity in a hybrid system. 


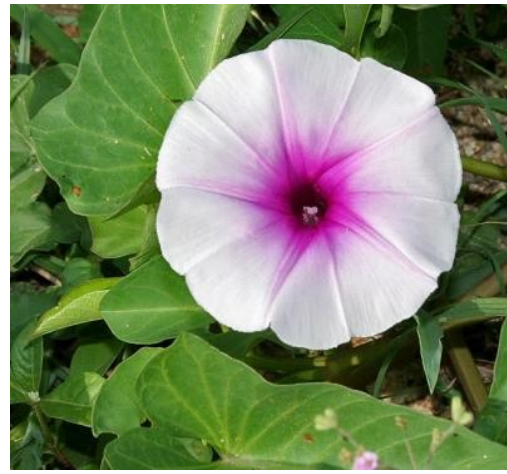

Fig. 5. Ipomoea aquatica [30].

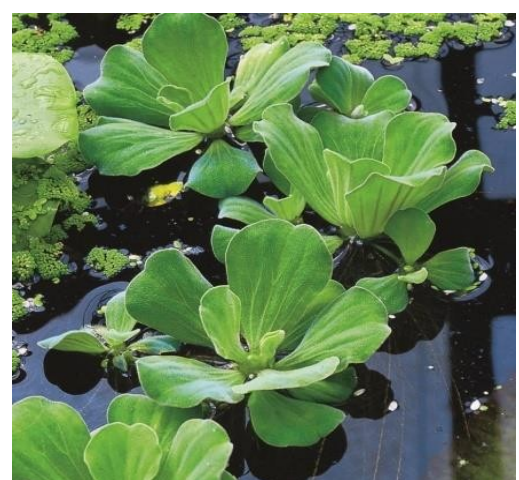

Fig. 6. Pistia stratiotes [31].

During photosynthesis, the microbial plant (PMFC) transmits part of what it emits to the roots. Then, the bacteria separate the nutrients causing electron transfer. Strategically positioned electrodes can receive electrons and thus produce electricity. A microbial plant produces current without impeding the development of the plant. Due to this, it can be used in agriculture to produce electricity and food at the same time.

The two systems were positioned in an area where the sun appears early in the morning and partial shade in the afternoon. These measures have been taken to protect plants from overheating. Microbial plants (PMFCs) were stacked individually in hybrid assemblies to amplify the power to simultaneously produce biomass and bioelectricity. The main assembly was made of ordinary glass with 9 individual cells (Fig.7a), each cell having a cotton cloth separator (Fig. 7b).

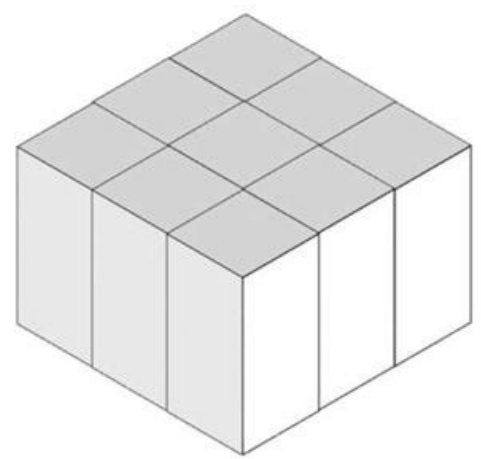

(a)

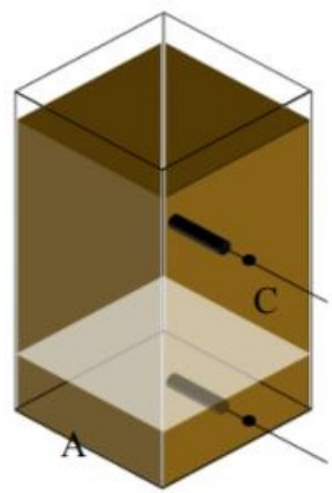

(b) $\mathrm{B}$

Fig. 7. (a) Design of stacked PMFCs (L x W x H: 18 in $x 18$ in $x 12$ in) and (b) Layout of the individual cells (A - cloth separator; $\mathrm{B}$ - cathode; $\mathrm{C}$ - anode) [23].

\section{Energy by gasification}

Study [24], analyzes the potential of transforming the residual biomass of Nile lettuce into energy through gasification technology. The technology consists of a system for handling ash and fuel and gasification (reactor, gas cooling, cleaning method). 
Pretreated biomass prevents biological degradation and helps store for a long time. A good design of the gasifier facilitates the transformation of biomass into coal. Then, the coal is modified to produce $\mathrm{CO}$ and $\mathrm{H}_{2}$ (fig.8).

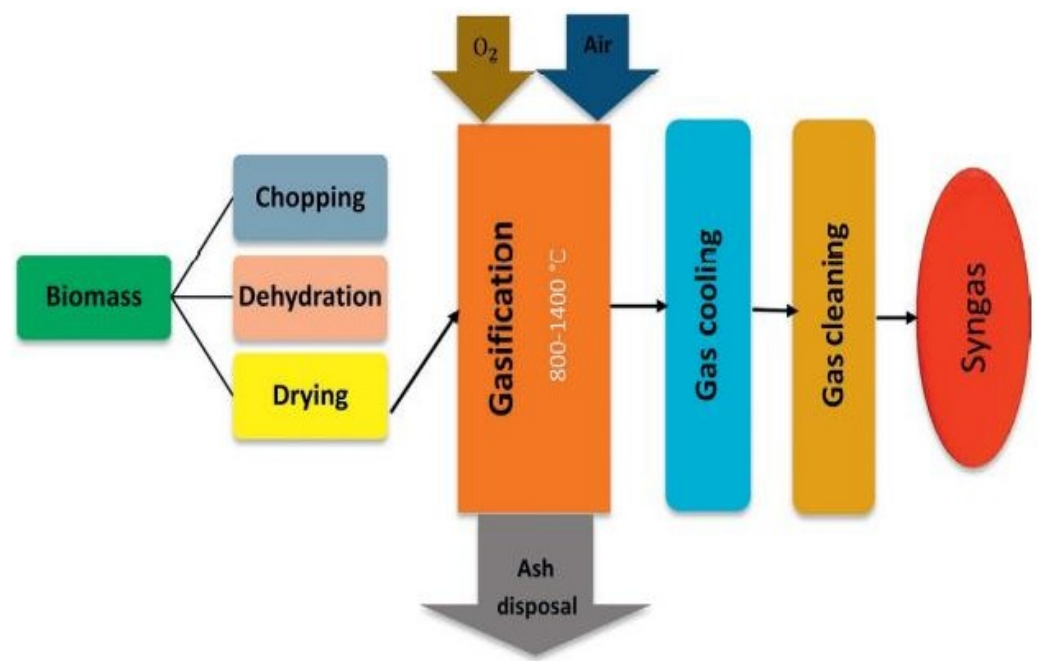

Fig. 8. Schematic diagram for syngas generation from biomass [24].

\section{Fertilizer and compost in a combined system}

Over time, scientists have conducted research to discover the most effective solutions for improving soil quality, with as few negative effects on the environment. Research has shown that the use of organic and inorganic materials as fertilizers supports plant growth and production.

Such an analysis was made in Indonesia, where farmers use biomass of aquatic plants as fertilizer. To determine the efficiency of using a combined treatment and with an improved technique, six treatments and three replicates were applied. The combination with P. stratiotes + Biotara + Decision Support System (DSS) was used to fertilize the rice crop. The results obtained showed that the application of the combined treatment had the highest productivity [25].

Another study was conducted, this time, to analyze the quality of compost by mixing rock phosphate with Nile lettuce (Pistia stratiotes) with and without effective microorganisms. Pistia stratiotes plants were dried for one week in the open field, after which the resulting material was shredded and sieved to reach the size of $5 \mathrm{~cm}$. After the analysis performed, it was found that organic waste can be transformed into valuable organic biofertilizers by adding lower doses of chemical nitrogen fertilizer and inoculation with efficient microorganisms.

Applying a combination of treatment, with Nile salad (WL), rock phosphate (RP), effective microorganisms (EM) and urea has a positive effect on the nutritional growth of the compost. It also enriches matter with phosphorus, compared to other treatments. The time required for composting is also reduced by adding EM solution and urea. Thus, Pistia stratiotes plants become a useful product by adopting this solution [26]. 


\section{Research results}

\section{Biomass}

The research results show that $P$. stratiotes can also grow in temperate areas with thermal water. Being a perennial aquatic plant with a rapid propagation, Pistia stratiotes biomass can prevent light from entering the water, thus influencing the evolution of fauna. In fig. 9, dry biomass of Pistia stratiotes collected from the shores of Lake Sava in March 2010 (a), seeds glued together in formations on the underside of the oldest leaves (b), characteristic barrel-shaped seeds (c), germinating the seeds after a month in the rearing chambers (d).

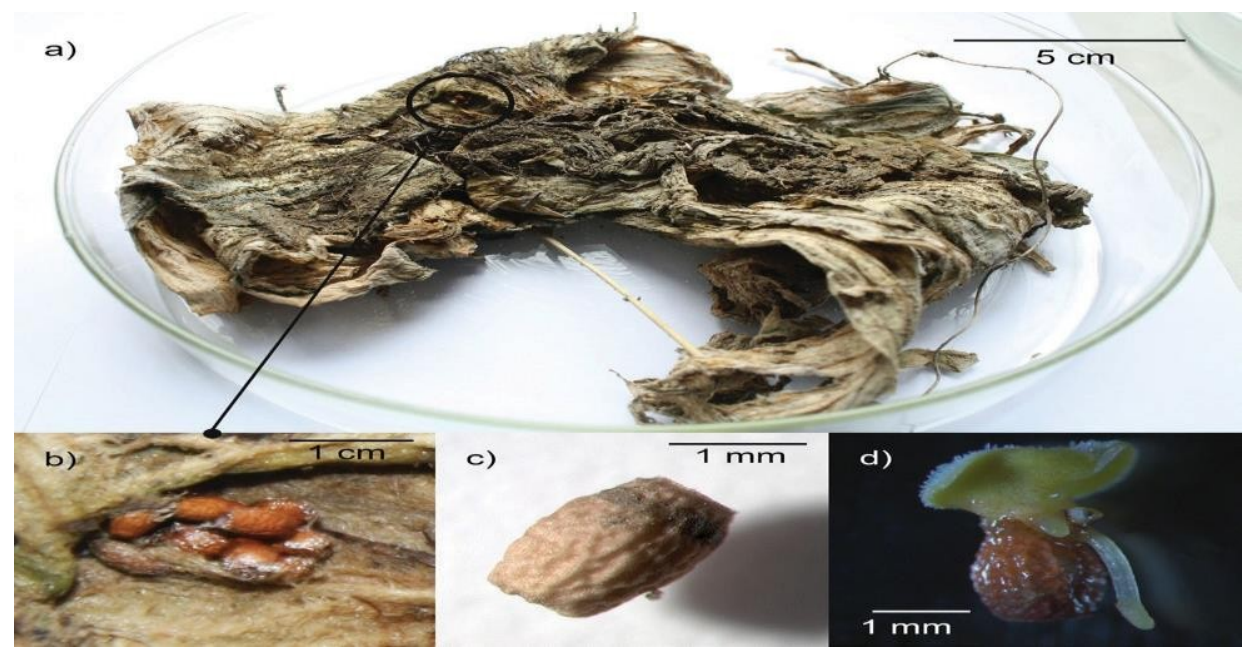

Fig. 9. Dried plant of Pistia stratiotes [18].

\section{Biofuels}

When the fermentation process is optimized, the biomass of Pistia stratiotes has an increased yield in ethanol production. The results of the study show that the potential of Pistia stratiotes for ethanol production was higher in the fermentation method SSF, fig. 11 than in the SHF method, fig. 10.
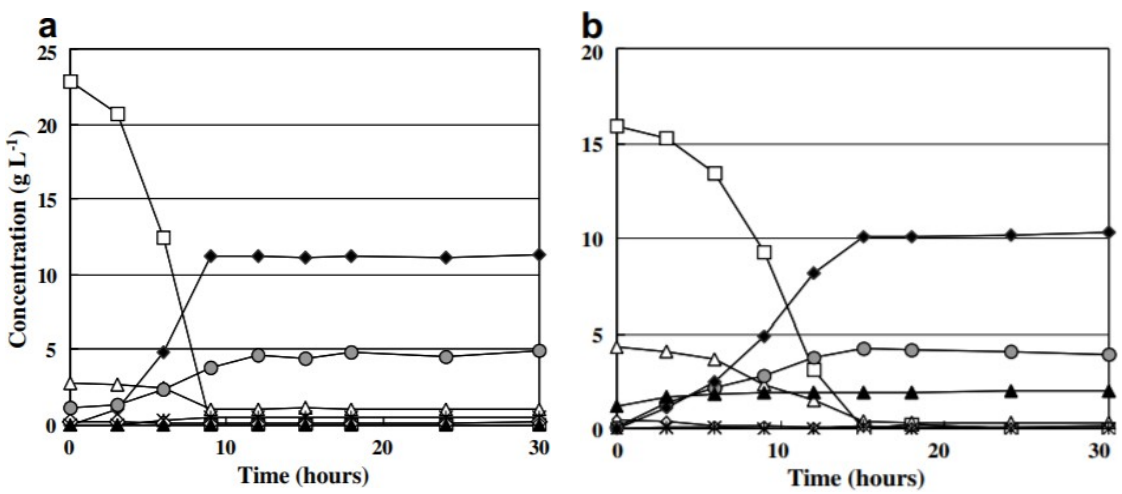

Fig.10. Ethanol production in SHF from water lettuce hydrolysate by Saccharomyces cerevisiae NBRC 2346 (a) and Escherichia coli KO11 (b). Symbols: $\square$, glucose; $\Delta$, xylose/ mannose/galactose; $\diamond$, arabinose; *, glycerol; $\boldsymbol{\Lambda}$, acetic acid; $\bullet$, biomass; $\bullet$, ethanol. 

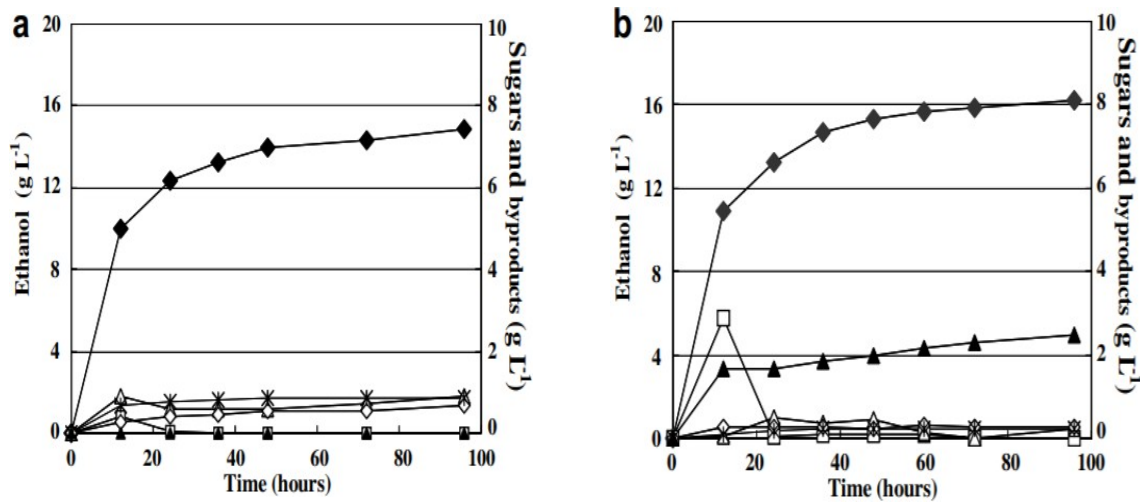

Fig.11. Ethanol and other byproduct concentrations in SSF fermentation of water lettuce leaves using Saccharomyces cerevisiae NBRC 2346 (a) and Escherichia coli KO11 (b). Symbols: ๑, glucose; $\triangle$, xylose/mannose/galactose; $\diamond$, arabinose; *, glycerol; $\mathbf{\Lambda}$, acetic acid; $\bullet$, ethanol [20].

The results of obtaining biodiesel by using Pistia stratiotes biomass are presented in tables no. 1, 2, 3 și 4 [22].

Table 1. Results of water lettuce (Pistia stratiotes) sample without addition of molasses (Only Leaf)

\begin{tabular}{|c|c|c|c|}
\hline Sample & $\begin{array}{c}\text { Total Reducing sugar } \\
\text { (TRS) }\end{array}$ & Alcohol content & Biodiesel \\
\hline Sample with $0.1 \%$ of HCL & 0.12 & 0.15 & \\
\hline Sample with $0.5 \%$ of HCL & 0.15 & 0.16 & \\
\hline Sample with $1.0 \%$ of HCL & 0.2 & 0.19 & 0.16 \\
\hline Sample with $1.5 \%$ of HCL & 0.29 & 0.32 & \\
\hline
\end{tabular}

Table 2. Results of water lettuce (Pistia stratiotes) sample without addition of molasses (Only Radicle)

\begin{tabular}{|c|c|c|c|}
\hline Sample & $\begin{array}{c}\text { Total Reducing sugar } \\
\text { (TRS) }\end{array}$ & Alcohol content & Biodiesel \\
\hline Sample with 0.1\% of HCL & 0.2 & 0.24 & \\
\hline Sample with 0.5\% of HCL & 0.3 & 0.31 & \\
\hline Sample with 1.0\% of HCL & 0.5 & 0.55 & \\
\hline Sample with $1.5 \%$ of HCL & 0.6 & 0.64 & 0.60 \\
\hline
\end{tabular}

Table 3. Results of water lettuce (Pistia stratiotes) sample with addition of molasses (Only Leaf)

\begin{tabular}{|c|c|c|c|}
\hline Sample & $\begin{array}{c}\text { Total Reducing sugar } \\
\text { (TRS) }\end{array}$ & Alcohol content & Biodiesel \\
\hline Sample with $0.1 \%$ of HCL & 0.29 & 0.3 & \\
\hline Sample with $0.5 \%$ of HCL & 0.32 & 0.31 & \\
\hline Sample with $1.0 \%$ of HCL & 0.35 & 0.4 & \\
\hline Sample with $1.5 \%$ of HCL & 0.4 & 0.45 & 0.44 \\
\hline
\end{tabular}


Table 4. Results of water lettuce (Pistia stratiotes) sample with addition of molasses (Only Radicle)

\begin{tabular}{|c|c|c|c|}
\hline Sample & $\begin{array}{c}\text { Total Reducing sugar } \\
\text { (TRS) }\end{array}$ & Alcohol content & Biodiesel \\
\hline Sample with $0.1 \%$ of HCL & 0.45 & 0.5 & \\
\hline Sample with $0.5 \%$ of HCL & 0.7 & 0.71 & \\
\hline Sample with $1.0 \%$ of HCL & 0.89 & 0.9 & \\
\hline Sample with $1.5 \%$ of HCL & 0.98 & 1.09 & 1.02 \\
\hline
\end{tabular}

\section{Energy}

Following the research, there were no significant differences in current voltage for the two terrestrial and aquatic plants, as shown in fig.12. Keeping the humidity, temperature and lighting at the same level, the different values observed were due to the physiological difference and the population of bacteria.

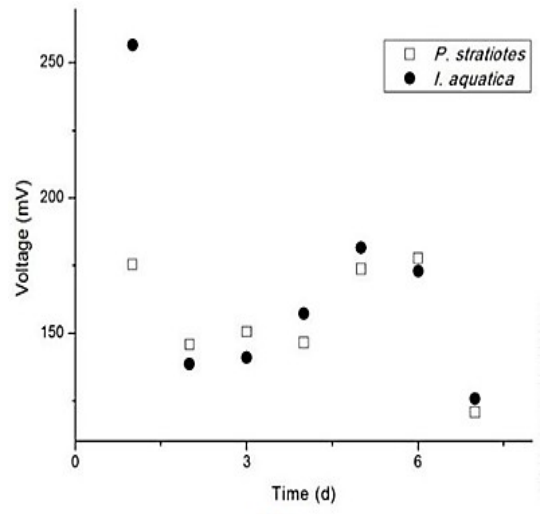

(a)

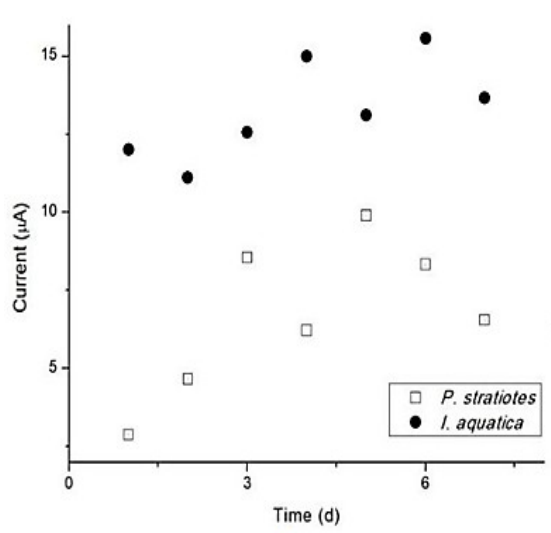

(b)

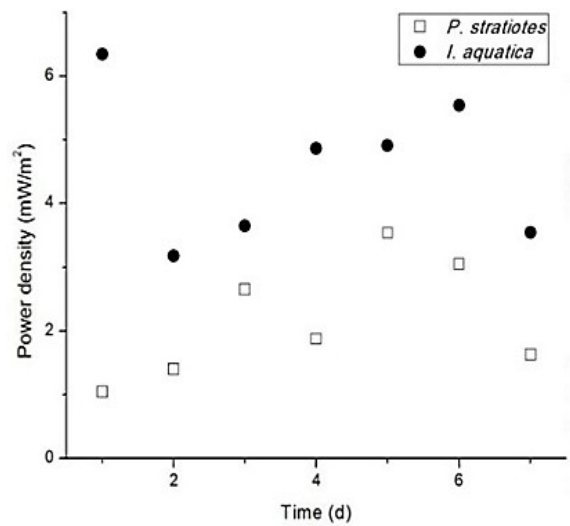

(c)

Fig. 12. (a) Average voltage readings of individual cells, (b) Average current readings of individual cells and (c) Average calculated power densities of individual cells [23]. 


\section{Fertilizer and compost}

The results of the experiment show that the application of the combined treatment of Pistia stratiotes (15 t / ha), bio-fertilizer Biotara/ha (25 kg), fertilization system DSS - K + $\mathrm{B}+$ DSS (50-kg urea / ha $+37 \mathrm{~kg} \mathrm{SP} 36 /$ ha $+24 \mathrm{~kg} \mathrm{KCl} \mathrm{ha)} \mathrm{had} \mathrm{the} \mathrm{highest} \mathrm{potential}$ compared to those obtained from local farmers and the control. The yield increased by $10.28 \%$ reaching $7.62 \mathrm{t} / \mathrm{ha}$ as shown in fig. 13 .

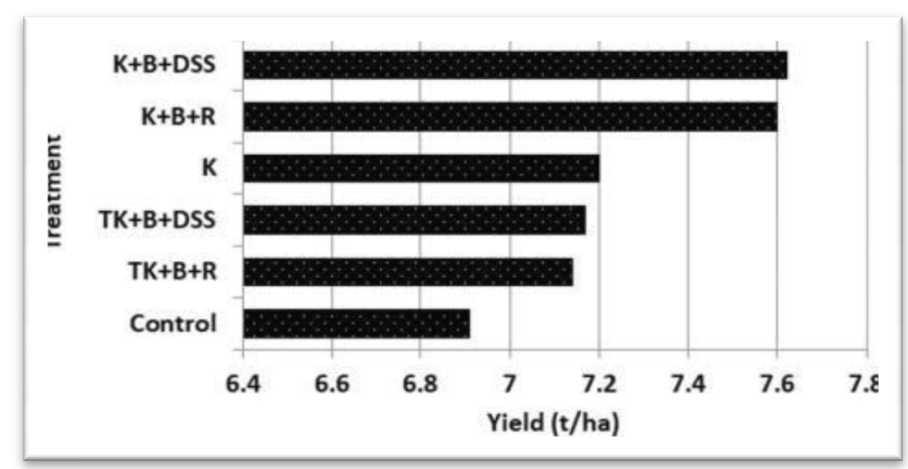

Fig. 13. Yield (t/ha) on treatment [25].

To obtain the biocompost, the following parameters were followed: maximum and minimum temperature, total precipitation and their duration, wind speed (table 5).

Table 5. Meteorological data during the composting period [26]

\begin{tabular}{|c|c|c|}
\hline Weather parameters & April 2010 & May 2010 \\
\hline Maximum temperature $\left({ }^{\circ} \mathrm{C}\right)$ & 33.8 & 36.9 \\
\hline Minimum temperature $\left({ }^{\circ} \mathrm{C}\right)$ & 16.4 & 19.2 \\
\hline Wind speed $(\mathrm{Km} /$ day $)$ & 51 & 74 \\
\hline Total rainfall $(\mathrm{mm})$ & 45.25 & 23.31 \\
\hline Rainfall days & 5 & 7 \\
\hline Pan Evaporation $(\mathrm{mm})$ & 5.94 & 7.76 \\
\hline Relative Humidity $(\%)$ & 60 & 52 \\
\hline
\end{tabular}

\section{Conclusions}

Population development and continuous growth of consumption are two vital aspects in the management of nonrenewable and renewable resources. In this context, the discovery and use of renewable sources is of great interest in supporting sustainable agriculture.

Although aquatic plants are most often considered harmful to the habitat in which they grow, they also have many benefits. Nile salad is used to treat wastewater, as an ornamental plant for aquariums, in phytoremediation of metals. 
To control the spread of invasive aquatic plants, researchers have shown that they can be used to improve soil quality, the plants that grow under its action, and the environment.

The aim of this paper was to present the aquatic plant, Pistia stratiotes, as a renewable energy source. The biomass of Nile Salad (Pistia stratiotes) has a diverse potential with applicability in obtaining biofuel, fertilizers and compost.

All these properties of Pistia stratiotes mean that in future research will continue to obtain new uses.

This work was supported by the Romanian Research and Innovation Ministry, through NUCLEU Programme, Project "PN 191002 03: "RESEARCH ON THE INTENSIVE GROWTH OF FISH IN THE POLYCULTURE SYSTEM AND THE COMPLEX VALORIFICATION OF THE BIORESOURCES (PLANTS) OF AQUATIC", contract no. 5N / 07.02.2019.

\section{References}

1. R.M. Jadav, Current Science 118, No.3, pp. 333-33 (2020);

2. P. Lloyd, Biodiversity,18(2-3), 124-125(2017);

3. I. Caba, D. Bordean et al., E3S Web of Conferences 112 (2019);

4. G. Ph. Robertson, Daedalus 144, Issue 4, pp.76-89 (2015);

5. M. S. Kang, Journal of Crop Improv (2020);

6. A. Rodriguez, M. Brijaldo at al., Ciencia En Desarrollo, 11(1), 63-80 (2020);

7. L. Hamelin et al., Renew. and Sust. Energ. Reviews100, pp.127-142 (2019);

8. J. J. Roberts et al., Renewable and Sustainable Energy Reviews, 41, 568-583 (2015)

9. G. Venturini, A. Pizarro-Alonso, \& M. Münster, Applied Energy, 250, 369-388 (2019);

10. M. A. Hanif et al., Env. Chem.: A Compr. Appr, pp.583-646 (2020);

11. F. Gerali, IEEE Engineering and Technology History Wiki. Hoboken, NJ: IEEE History Center (2020);

12. P. Găgeanu, I. Găgeanu, G. Bunduchi, and A. Zaica, E3S Web of Conferences 112 (2019);

13. M. Papale, I. Romano, I. Finore at al, Microorganisms, 9 (2), 218 (2021);

14. R. Kanissery, Citrus Ind. Magazine (2021);

15. T.Sayara, R. Basheer-Salimia, F. Hawamde, \& A. Sánchez, Agronomy 10 (11) (2020);

16. D. Chapman, J.A.Coetzee et al., Bulletin OEPP/EPPO Bulletin 47(3) (2017);

17. D. Beňová, K. Mareš, P. Hutla, Tatiana Ivanova, Jan Banout, M. Kolaříková, Agronomy, 11(1), 169 (2021);

18. M. Jaklič, Š. Koren, N. Jogan, Acta Bot. Croat 79 (1), 35-42 (2020);

19. E. Corneli, A. Adessi, E.J. Olguin, G. Ragaglini et al., Journal of Appl. Microbiology (2017);

20. D. Mishima, M. Kuniki, K. Sei, S. Soda, M. Ike, M. Fujita, Bio. Tech. 99, Issue 7, 2495-2500 (2008);

21. K. Whangchaiet al., Bioresource Tech. Reports 14 (2021);

22. S. Bachhav et al., Production of Biofuel using Water Lettuces (Pistia Stratiotes), IRJET, vol. 6, Issue 5 (2019);

23. K. R. S. Pamintuan et al., IOP Conf. Ser.: Earth Environ. Sci.191 (2018); 
24. S. Kathi, Bioremediation and Bioeconomy, pp. 111-128 (2016);

25. A. Hairani, M. Alwi, K. Anwar, BIO Web of Conferences 20 (2020);

26. S. Kanwal, S.Iram et al., African Journal of Microbiology Research 5 (14), pp. 17841793 (2011);

27. https://microbewiki.kenyon.edu/images/thumb/4/47/Rpalustris.png/300pxRpalustris.png;

28. http://www.healthspectra.com/wp-content/uploads/2018/02/E-Coli-infection-HS02.jpg;

29. https://biologydictionary.net/wp-content/uploads/2020/06/Saccharomyces-

Cerevisiae.jpg;

30.https://upload.wikimedia.org/wikipedia/commons/b/b4/Ipomoeaaquatica(Marsh_Glory)f lower_W_IMG_0405.jp;

31.https://img.crocdn.co.uk/images/products2/pl/20/00/02/24/pl2000022461.jpg?width=94 0 \&height $=940$. 